\title{
The experiences of individuals with schizophrenia using the Model of Occupational Self-Efficacy in enhancing work skills and returning to work in the open labour market in Western Cape, South Africa.
}

\author{
*lesrafeel Abbas, BSc OT (UCT), MSc OT (UWC). https://orcid.org/0000-000 I-5695-3976 \\ Lecturer, Division of Occupational Therapy, Department of Health and Rehabilitation Sciences, University of Cape Town \\ Mogammad Shaheed Soeker. BSc OT (UWC), MSc OT (UWC), PhD OT (UWC). \\ https://orcid.org/0000-000 I-5382-I855 \\ Head of Department, Department of Occupational Therapy, Faculty of Community Health Sciences, University of the Western Cape
}

Introduction: Evidence suggests that supported employment strategies improve the rates of employment for individuals with schizophrenia. The Model of Occupational Self-Efficacy (MOOSE) is such a strategy aimed at enhancing work skills and facilitating return to work (RTW). The aim of the current study was to explore the experiences of individuals with schizophrenia about the use of the MOOSE in enhancing work skills and facilitating RTW in the open labour market.

Method: A qualitative research project with an interpretivist paradigm explored the experiences and perceptions of nine participants diagnosed with Schizophrenia. Two occupational therapists participated as key informants. Data were collected by means of semistructured interviews and analysed using inductive thematic analysis.

Results: Barriers and facilitators to the use of the MOOSE were revealed. More importantly, the MOOSE enhanced the development of worker identities and contributed to the successful adaptation of worker roles in the RTW process of individuals with schizophrenia in the open labour market.

Conclusion: The MOOSE is an effective supported employment strategy for persons with schizophrenia. Factors such as client-centred practice, the presence of social support, and ongoing therapeutic support contributed to the participants' successful RTW experience.

Key words: Schizophrenia, supported employment strategies, Model of Occupational Self-Efficacy, return to work, perception, experience

\section{INTRODUCTION}

In recent years, the occupational functioning of individuals with mental illness, particularly those with a diagnosis of schizophrenia, have become a target for intervention'. Schizophrenia is described as a disabling brain disorder affecting the socio-occupational functioning of individuals in their daily life activities ${ }^{2}$. In particular, these individuals experience major issues in social functioning ${ }^{3}$, with return to work (RTW) and maintenance of employment being one of the main areas in which they experience difficulty ${ }^{4}$. In order to improve functioning and facilitate the process of individuals with schizophrenia returning to competitive employment, supported employment is recommended and has been recognised as a form of evidence-based practice ${ }^{5}$.

This paper reports on the findings of a study, which aimed to explore the experiences and perceptions of individuals with schizophrenia about the use of the Model of Occupational Self-Efficacy (MOOSE), as a supported employment strategy, in enhancing work skills and facilitating RTW in the open labour market ${ }^{6}$. The MOOSE is a client-centred occupational therapy practice model used to provide support and facilitate the process of RTW, whilst taking into consideration how the immediate environment may influence the performance of worker roles ${ }^{7}$. Since the MOOSE was originally developed for individuals with traumatic brain injury ${ }^{7}$, it was adapted for individuals with schizophrenia for the purpose of the current study $^{6}$. The objectives of the current study ${ }^{6}$ were to explore and describe the challenges and facilitatory factors experienced by these individuals regarding the use of the MOOSE in RTW. Additionally, to describe the perceptions of these individuals with regard to how the MOOSE helped them develop their identity as a worker and ability to adapt to their worker roles upon RTW. As the MOOSE is a newly developed model, there was a need to examine its use as a supported employment strategy for individuals with schizophrenia. This study was therefore the first of its kind and revealed pivotal information regarding the use of the MOOSE in the RTW process.

\section{LITERATURE REVIEW}

The national population estimates of 2017 indicated that South Africa has a population of 56.52 million $^{8}$. Currently, only $0.7 \%$ of the country's economically active people are those with disabilities $^{9}$ which - if compared to the $0.9 \%$ reported in $2014^{10}$ shows regression, despite affirmative legislation to promote the employment of persons with disabilities. The employment rate amongst individuals with schizophrenia is especially low, despite their willingness to return to work (RTW) ${ }^{11,12}$. A global study on the epidemiology of schizophrenia ${ }^{4}$ found that only about $2 \%$ of individuals with schizophrenia in Poland were employed on a full-time basis, with approximately $20 \%$ in the United States of America and Europe ${ }^{4}$. Importantly, its results suggest that more 
than half of individuals with schizophrenia could potentially RTW during remission of schizophrenia ${ }^{4}$, however a lack of effective interventions such as supported employment ${ }^{13}$ and unconducive working environments ${ }^{14}$ remain a major challenge in the RTW process. Similarly, a South African study ${ }^{15}$ indicated lack of awareness and a poor understanding of disability by employers which contribute to the ineffective integration of people with disabilities within the workforce, which could explain the low employment rate of this population group.

Supported employment aims to facilitate the process of RTW for individuals with schizophrenia (and other mental illnesses) and focuses on increasing the likelihood of these individuals obtaining and maintaining employment ${ }^{\prime}$. Evidence-based practice confirms supported employment as a preferred intervention strategy when facilitating RTW in the open labour market ${ }^{5}$. It is however, still a relatively new concept within South Africa, with few available programs and models ${ }^{5}$. Internationally, there are supported employment strategies such as the Individual Placement and Support Strategy (IPS) which aims to enhance vocational outcomes and promote an individuals' self-esteem and overall well-being ${ }^{16}$. However, minimal evidence exists with regard to IPS addressing job maintenance, instead of initial RTW only ${ }^{17}$. Furthermore, as a result of IPS being an expensive strate$\mathrm{gy}^{16}$, its access to individuals with disabilities is limited, with less than $1 \%$ of individuals with schizophrenia in the United States receiving IPS as a supported employment strategy in $2009^{18}$. The Clubhouse model is another supported employment strategy that aims to assist individuals to participate in competitive employment, reduce readmission to hospital, and improve quality of life ${ }^{19}$. However, the Clubhouse model is similarly criticized for its deficit in providing reliable access to individuals with disability and for providing ongoing support after an individual has RTW ${ }^{20}$. Furthermore, the Clubhouse model is well-known for its quick job placement of individuals into any employment, instead of employment that are meaningful and purposeful to the individual ${ }^{20}$. Owing to this, many individuals with disability make use of alternative supported employment strategies when $\mathrm{RTW}^{18}$. The researcher therefore advocated for the MOOSE as a supported employment strategy in enhancing work skills and facilitating the RTW for individuals with schizophrenia.

Developed in South Africa, the MOOSE is a client-centred, evidence-based model demonstrating an $80 \%$ success in RTW for individuals with disabilities ${ }^{21}$. The MOOSE has a client-centred dynamic staged approach. In stage one, known as a strong belief in functional ability, the individual becomes reflective by means of introspection facilitated by an occupational therapist. Stage two of the model focuses on the use of self, enabling participants to regain control of their life situation and realise their self-sufficiency. Stage three of the model is known as the creation of competency through occupational engagement. Throughout stage three, the individual focuses on the occupational performance area of work. Self-efficacy is enhanced by means of independent functioning within the work environment to the extent that the individual experiences, through continuous successful engagement in his or her occupational role, an improved ability and competency to be able to RTW and successfully maintain employment independent$\mathrm{ly}^{22}$. Stage four of the model, called the capable individual, is the final stage where individuals are encouraged to self-reflect and consider their involvement in the previous stages of the model as well as to realise their success in the engagement and participation of their occupational role as a worker.

\section{METHODOLOGY}

This study was positioned within the interpretivist paradigm, using an exploratory and descriptive research perspective. A qualitative research approach was used and allowed the researcher to study and interpret phenomena based on the meaning participants brought to these phenomena ${ }^{23}$.

\section{Population and sampling}

A purposive sample of 16 individuals from a government hospital in the Western Cape was identified based on the following inclusion criteria: the participants were diagnosed with schizophrenia according to the DSM ${ }^{5}$, were employed in the open labour market prior to their admission to hospital, lived in the Western Cape Metropole, were over the age of 18 years, and able to understand and communicate effectively in the English and/or Afrikaans languages. Individuals who showed evidence of significant and habitual substance abuse, and individuals with active symptoms related to a psychiatric condition were excluded from the study. Eleven individuals volunteered to participate in the study and nine of them concluded their participation. Two occupational therapists were purposively sampled as key informants to enrich and gain dense insight into the research topic.

\section{Data Collection and Analysis}

Data were collected using face to face, semi-structured interviews designed to ensure similar content of questioning ${ }^{24}$. The researcher interviewed each of the nine participants twice. The first interview was conducted during stage four of the model and the second, one month after their employment in the open labour market. One semi-structured interview was conducted with each of the two key informants of the study. The duration of each of the interviews ranged between 40 to 60 minutes. Interviews were audiotaped and transcribed verbatim. The researcher reviewed all transcriptions for errors or exclusions of data and manually analysed the data using inductive thematic analysis. The researcher reflected and consulted with his supervisors throughout the research. The sixstep analysis process as described by Braun and Clarke ${ }^{25}$ was used: (1) familiarisation of data, (2) generating initial codes, (3) merging similar codes into categories, (4) searching for themes (5) defining and naming themes and (6) producing the report.

Strategies such as credibility, dependability, confirmability, and transferability were employed to ensure trustworthiness of the data ${ }^{26}$. Credibility was ensured by audio-tape recordings of the semi-structured interviews, which allowed the exact representation of the opinions of the participants and ensured that the data were truthful. Member checking ${ }^{27}$ was used, providing participants with the opportunity to read, comment on and contribute to the results and discussion of the study. Dependability was ensured by an audit trail ${ }^{24}$ for all methodological decisions made within the study. Confirmability was ensured through the process of researcher reflexivity ${ }^{27}$ in the form of a journal to clear personal biases and assumptions. Transferability was ensured by providing thick descriptions of the study population, research method, context, and a rich presentation of the findings of the study.

Ethics approval for the study was obtained from the University of the Western Cape's Senate Research Committee (ethics reference number: HSI6/5/46). Permission to conduct the study with patients from a government hospital was obtained from the Western Cape Department of Health. The participants were informed about the nature of the study and written informed 
Table I: Participant and Key Informant demographics

\begin{tabular}{|l|l|l|l|l|l|}
\hline Participants & Gender & Education & Age & Work experience & Diagnosis \\
\hline PI & Male & Grade I2 & 3 I & General assistant & Schizophrenia \\
\hline P2 & Female & Certificate & 43 & Graphic designer & Schizophrenia \\
\hline P3 & Male & Certificate & 34 & Announcer & Schizophrenia \\
\hline P4 & Male & Grade I0 & 37 & Administrator & Schizophrenia \\
\hline P5 & Male & Grade II & 36 & Chef & Schizophrenia \\
\hline P6 & Male & Grade 8 & 22 & General assistant & Schizophrenia \\
\hline P7 & Male & Diploma & 29 & Lab technician & Schizophrenia \\
\hline P8 & Male & Grade II & 36 & Security guard & Schizophrenia \\
\hline P9 & Male & Diploma & 28 & Salesman & Schizophrenia \\
\hline Key Informants & Gender & Education & Age & Work experience & \\
\hline KII & Female & BSc OT & 26 & $\begin{array}{l}\text { Senior OT: } 5 \text { years of working experience in } \\
\text { mental health }\end{array}$ \\
\hline KI2 & Female & Certificate & 46 & $\begin{array}{l}\text { OTT: I8 years of working experience in mental } \\
\text { health }\end{array}$ \\
\hline
\end{tabular}

consent was obtained from them. Confidentiality and anonymity were maintained by not using participants' names in the research study and by storing information on a password-protected computer and in the university's research database, accessible to the researcher and his supervisors only.

\section{FINDINGS}

\section{Demographics}

Table I shows participant and key informant demographics. Of the nine participants, eight participants were male and one female. Three participants were between the ages of 20-30 years, five between 3 I -40 years, and one over 4 I years old. Five participants indicated that they were single, and four that they were in a relationship or married. Their education levels ranged from grade 8 to post grade 12 training. The key informants were both female and working in an occupational therapy department within a Western Cape hospital.

Four themes emerged from the data and are described below.

\section{THEME ONE: FACTORS NEGATIVELY AFFECTING THE SUBJECTIVE EXPERIENCE OF PARTICIPANTS ABOUT THE USE OF THE MOOSE IN RTW.}

Theme one discusses the negative factors affecting the participants' subjective experiences of the use of the MOOSE. This theme is presented in two categories:

\section{Category I: External challenges impacting on the process of the MOOSE}

This category describes the participants experiences of the challenges they faced as a result of factors external to that of the model itself.

\section{Lack of therapist and family support}

Participants indicated that when the MOOSE, and therefore the presence of therapists' support was not available to them and their employers, their employers did not understand their illness and there- fore experienced difficulty in managing them within their workplace. As a result, employers were unaware about how they could reasonably accommodate their employees whilst considering their illness.

This programme [MOOSE] helped for them [employer], because at first, when this programme was not there, they didn't understand what was wrong with me... and then this programme was there, then you [OT], when you were in touch with them, it helped them to understand the illness better. (P7)

The lack of family support in the RTW process proved to be a challenge as some participants often appeared to be pre-occupied and distressed about their current life circumstance, thus essentially contributing to a challenging RTW process.

... because I was sick, was to stay at Hospital, for 2 months... it wasn't, I wasn't feeling good, because I was struggling about food, clothes, everything. (P8)

Employers' and colleagues' lack of willingness to become involved Some participants reflected how the insufficient support they received from their employers and colleagues negatively affected their working abilities. Participants also shared their fear of stigmatisation, and how it negatively impacted their RTW process.

...no one knew that I was on medication... I had to hide it, my medication, I had to drink it skelmpies [discreetly] so that no one sees, that was very difficult for me... (P5)

Another participant's previous employer did not want him to RTW when he arrived for duty at his workplace as a result of him having a mental illness.

Yes, the company don't want to give me the job back... to start work because I was sick. (P8) 
Traditional and cultural considerations influencing the use of the MOOSE in RTW

Participants emphasised how traditional and cultural beliefs had the potential to influence their perception of their illness and its symptoms. These false perceptions often led to some of the participants misunderstanding their illness - essentially resulting in a relapse and therefore readmission to hospital as they could no longer cope within their roles. One participant stopped the use of his prescribed medication as he believed that he was hearing the voices of his ancestors, and not auditory hallucinations related to the symptoms of schizophrenia.

At stage three, I wasn't taking my medication, I came to work... so at that time I couldn't [work], I was at the denial stage at that moment, l'll say. (P7)

\section{Category 2: Stage-specific challenges experienced within the MOOSE}

Within this category, it emerged that none of the participants experienced challenges in stage two and stage four of the model. However, challenges were experienced in stage one and stage three of the model.

A key informant was of the opinion that, due to the MOOSE being a relatively new model, the initial use thereof may be challenging for therapists who are applying it in practice, as well as clients utilising it for the enhancement of their work skills and RTW.

I think it will be challenging initially... because you don't know it and it's new to you and it's new to the patient so uhm, confusion... (KII: key informant)

Stage one: Reflecting is a difficult process.

Participants were of the opinion that introspection and self-reflection (stage one) was a difficult process, and that engaging in these discussions often triggered ones' emotions as one thought about one's own life and where one was at that specific point in time.

Made me sad... made me depressed... some questions even made me angry... cause it takes you back to what things happened in your life... (P4)

Stage three: Engaging in the occupational process of RTW may be challenging

Stage three was seen as of utmost importance as it is in this stage that the individuals with schizophrenia's work specific skills were enhanced. Some participants who were returning to work initially experienced difficulty with concentrating on work tasks and adhering to work routines.

Trying to, to set the plan and to stick to the plan, to the goal... trying to stick to routine and to concentrate. (P2)

Other participants who were in the process of seeking employment experienced immense frustration, as they were not sure whether they would find employment or not.

Stage three... that was a bit tricky for me, because like waiting for work and [the] frustration waiting for work. (PI)
THEME TWO: POSITIVE EXPERIENCES AS A RESULT OF THE USE OF THE MOOSE IN RTW

Theme two describes the positive experiences that the participants had encountered during the use of the MOOSE. These are presented in two categories:

\section{Category I: Gainful and meaningful experiences: meeting basic needs}

This category highlights the participants' experiences on how participating in the MOOSE essentially resulted in beneficial gains such as an improved self-esteem and self-efficacy, enhanced willingness to engage in various occupational roles, and essentially successful RTW.

...yes, I experienced something beneficial, I obtained a job, I got self-respect, confidence. (PI)

A client-centred focus to rehabilitation

Participants experienced the RTW process as being meaningful and were of the opinion that the MOOSE had the ability to be flexible in such a manner that it provided holistic support and was able to meet the needs of each participant respectively.

Like the support outside of the hospital... that it's still there... cause this is the support that I need from them [therapists]... ongoing support, that's like always there for me, what $I$, other people don't get. (PI)

Earning an income facilitates independence

Obtaining employment and earning an income contributed to the participants experiencing a sense of achievement, self-worth, and essentially independence.

...that I have money of my own that I don't need to steal for money...or borrow from people, that I'm actually working, and that people are proud of me also. (PI)

\section{Category 2: Stage-specific beneficial experiences within the MOOSE}

Within this category it emerged that the participants specifically experienced stage one, two, and three to be beneficial in their RTW process. Participants were of the opinion that the various stages and processes of the MOOSE facilitated them in enhancing their work skills and improving their working abilities.

I'm a better worker... uhm, like these stages did help me, by going through the stages and learning... it's a great opportunity to fulfil my uhm, my goals... (P6)

Stage one of the model allowed participants to realise their potential and become goal-directed

Upon introspection and self-reflection, the participants realised their true potential within stage one of the MOOSE. This realisation contributed to the enhancement of the participants' confidence and self-esteem, thus facilitated their ability to become goal-directed.

I think stage one was very helpful... in allowing them, to build their confidence and enhance their self-esteem, and thus giving them the ability to want to face things. (KI2: key informant) 
Stage two of the model equipped individuals with the ability to face workplace challenges

Participants were of the opinion that stage two of the model assisted them in regaining autonomy and equipped them with the necessary skills and abilities to be self-sufficient and therefore essentially able to successfully return to their worker roles independently.

...think stage two helped me to, to return to work... we learn about life skills... and the things that you going to face when you are out there in the work environment... stage two helped me to become [a] better [worker]. (P7)

Stage three of the model facilitated a positive transition into the workplace

It was noted that the participants' motivation, self-confidence, and perspective of their ability to return to their worker roles and perform work tasks independently was enhanced as they participated in this stage of the model. Participants were initially able to assess their ability to perform work tasks and had the opportunity to improve and enhance their work skills as needed.

At first it was difficult [being at work], so I had to return back to the hospital [OT] and then I gained more life skills, and when I came back again [to work] I was fine..." (P7)

\section{THEME THREE: AN ENHANCED SELF- EFFICACY FACILITATED THE DEVELOPMENT OF A BETTER ME}

Theme three discusses how an enhanced self-efficacy contributed to an improved overall well-being of the participants. This theme is presented in two categories:

\section{Category I: An enhanced self-concept facilitated a positive identity}

This category discusses the participants' experiences of how the development of an enhanced self-concept facilitated a positive identity and perspective of themselves and their ability to reach their potential and successfully achieve their desired goals.

Working independently... yeah coming back to work, being your own self... it almost felt like l'm going back to being my old self again. (P7)

\section{Having a positive outlook on life}

Participants perceived themselves in a more positive manner over time, resulting in them having a more positive attitude towards their lives.

...cause I'm feeling very positive about myself and positive about the future also... just to wake up every morning. (PI)

Being able to tap into ones' potential and realise ones' own capabilities

It was noted that participants became more conscious of their true potential and capabilities.

I wasn't as confident to, to do the work, I feel more positive about it [now]... it [the MOOSE] help me... (P2)

A key informant described her experience of how the use of the MOOSE enabled a client to assert, make decisions, and improved his confidence in his ability to approach and express his opinion to others. She said:
The patient grew, uhm, from a low self-esteem, speaks up for himself, making certain decisions for himself... uhm, the confidence to go to [approach] other people... (KI2: key informant)

\section{Category 2: Being able to live a meaningful and independent life}

It was noted that as the participants' independence improved within their worker roles as they RTW, so did their perspective of themselves being a capable individual.

The programme helped a lot, before I had no self-esteem, I was depressed, thought I wasn't gonna get a job but the programme helped me a lot through obtaining employment and gaining my confidence and self-respect. (PI)

Becoming independent: standing up for oneself

It was noted that being employed and engaging in the occupation of work had many benefits for participants, beside financial gains. Essentially, the participants became empowered and independent in their occupational roles, resulting in them experiencing an improved meaningful life and an enhanced self-efficacy. Similarly, being independent and having the ability to stand up for oneself' contributed to the participants' successful RTW experience and facilitated their adaptation to the workplace. As one key informant stated:

I always tell employees, work has more than just financial gains. Patients are able to also establish a sense of belonging at work, they are able to uhm, they are able to relate to other people without mental illnesses also... they can uhm, integrate into society... because of the worker role, it gives you a sense of purpose, you have a sense of agency, you're able to stick to a routine, which is all of the things that are needed to stay healthy for longer. Those are the things that work on its' own offers the patients. (KII: key informant)

Having insight into one's illness contributed to an improved meaningful life

Participants who had significant insight and knowledge into their illness were better able to make informed decisions whilst considering their health and well-being.

I've benefitted that, that I came to understand that l'm a person who's got a mental illness and it will stay with me for the rest of my life. It can be treated as any chronic disease, if I take my medication... l'd go back to be that normal person again, who I was... before I got sick. (P7)

\section{THEME FOUR: ADJUSTING TO WORK, IT IS POSSIBLE!}

Theme four describes how the participants adapted to their worker roles. This theme is presented in two categories:

\section{Category I: The enhancement of an individual's intrinsic abilities in order to facilitate workplace adaptation}

It was noted that as the participants' intrinsic abilities were improved whilst they RTW, they were better able to adapt to their worker roles, thereby contributing to the successful engagement in their working environment.

...I have confidence in myself... like now, I self-respect a lot, and people respect me now when I'm back at work... and the confidence level for myself is like through the roof actually. (PI) 
The improvement of one's job specific skills positively contributed to workplace adaptation

It was noted that the improvement of the participants' job specific skills and performance components required within the area of work facilitated the adaptation of their worker role and ability to successfully RTW and engage in work tasks with ease. Through the process of the MOOSE, a participant and his therapist sought various ways in which he could adapt and improve his work skills so that he was able to complete job tasks with ease.

Just difficulty to counting [the linen]... and lifting up the bags and throwing the bags... that I haven't worked in a long time... so it's taking time to adapt... and just focusing on my task at hand. (PI)

The improvement of life skills positively contributed to workplace adaptation

It was noted that the improvement of the participants' life skills facilitated the adaptation of their worker role and ability to successfully RTW and engage in work tasks with ease. A key informant alluded to how the enhancement of self-esteem positively influenced a participant's concentration and attention span. She further mentioned how the participant was better equipped to make decisions for himself and was therefore better able to adapt to his worker role. She said:

It boosts his self-esteem, uhm, it enhanced his attention, concentration span... uhm, he could make more decisions for himself. (KI2: key informant)

\section{Category 2: Environmental factors requiring adap- tation in order to facilitate workplace adaptation}

It was noted that in order to facilitate workplace adaptation and ensure successful RTW, the participants' work environment needed to be accommodated and adjusted in a manner that contributed to a more conducive working environment and thus enabled participants to RTW with ease. As one key informant stated:

.. and he uhm, worked far away from home, it normally took him like 3, 4 hours to travel and then the work management uhm, said that they would accommodate him by giving him placement, uhm reasonable accommodation on the site where he is going to work, they gave him less uhm, responsibilities, he was a Grade $B$ [security] officer... but they did not decrease his salary, they just lessened his responsibilities. (KI2: key informant)

\section{Reasonable accommodations in the workplace facilitated a} successful RTW

Participants were of the opinion that the reasonable accommodations made within the workplace facilitated and contributed to an easier successful RTW. It was noted that participants experienced less challenges when RTW after they had been reasonably accommodated in the working environment.

Everything seems to be easier, they changed my working environment... ya due to my employer... he saw that I needed some accommodation change of place... from this position to the other position... so he gave me light duties only for, just for me to, to have a clear understanding of my well-being and my illness... and to work lighter than before. (P3)
Family support is integral to successful adaptation in the workplace and overall well-being

Participants were of the opinion that the reasonable accommodations made within the workplace facilitated and contributed to an easier and successful RTW. It was noted that participants experienced less challenges when RTW after they had been reasonably accommodated in the working environment.

Everything seems to be easier, they changed my working environment... ya due to my employer... he saw that I needed some accommodation change of place... from this position to the other position... so he gave me light duties only for, just for me to, to have a clear understanding of my well-being and my illness... and to work lighter than before. (P3)

Employer and colleagues' support is integral to successful workplace adaptation in the workplace and overall wellbeing

Participants were of the opinion that receiving support from their employers and colleagues, who understood their mental illness, allowed them to be perceived as a regular employee who will become accustomed to the challenges being experienced in the working environment, and not only as individuals with disabilities- this support and consideration of the participants' employers and colleagues facilitated their successful RTW in the open labour market.

Yes I do get support from my colleagues, they understand... and its, they don't see it as a disability, they just see it as a new person that's starting to work, and that they will get use to like obstacles they will face in the beginning... (PI)

\section{DISCUSSION}

External challenges reported with the use of the MOOSE were lack of therapist and family support, lack of interest and willingness from employers and colleagues, and cultural considerations. The latter has been reported in South African studies to have a significant influence on the development, presentation, cause, and outcome of psychopathologies such as schizophrenia ${ }^{28}$. The current study found that cultural beliefs and misconceptions led to some of the participants misunderstanding their diagnosis of schizophrenia, ultimately resulting in them relapsing and being readmitted to hospital.

Two stages of the MOOSE were identified as being a challenge and a facilitator, that is stage one and stage three. The current study found that stage one was a challenging process for the participants as it triggered their emotional responses. This coincides with another study where individuals with mental illness engaged in the process of experiential sharing and reflecting and experienced feelings of emotional distress as a result of identifying negative aspects of one's life ${ }^{29}$. In contrast, the current study found that the participants' confidence in their abilities was enhanced as they engaged in the process of reflection. Similarly, another study found that through the process of reflection, participants acknowledged positive changes and development, as they ultimately realised their true potential ${ }^{30}$.

The current study found that participants were anxious and experienced difficulty with work tasks upon their initial RTW during stage three. This corresponds with another study3I, where individuals with mental illness experienced difficulties related to their worker roles upon their initial RTW, as they needed to become accustomed to their new responsibilities in their RTW process. In contrast, the current study found that within stage 
three, participants were able to assess their working abilities and thus had the opportunity to enhance their skills where necessary. Similarly, another study found that the engagement in occupations and RTW provides individuals with the opportunity to develop necessary skills to adapt to their worker roles as needed, ultimately ensuring a successful RTW ${ }^{32}$. In addition to these stages, stage two, as described in theme two, was identified as a facilitator only, as it equipped participants with the necessary skills that enabled them to confidently face workplace challenges and ultimately RTW with success. Another study found that through this process, participants were able to develop insight into their limitations and resolve these limitations before returning to work ${ }^{33}$. Evidence exists which establishes that having insight into one's illness has a strong influence on the clinical outcome, treatment compliance, number of hospitalisations, social and interpersonal functioning, and vocational rehabilitation ${ }^{34,35}$. Based on the findings of the current study, participants who understood the nature of their illness demonstrated an enhanced and improved overall functioning, including their health and well-being. Participants were essentially able to live and work independently, required minimal support, and experienced an enhanced self-efficacy, as described in theme three. Furthermore, an inherent feature of the MOOSE, being a client-centred model, was identified as facilitator in the current study. Participants reported that with the MOOSE, they received ongoing, tailor-made, clientcentred support from their therapists, thus enhanced their ability to engage in their worker roles. Client-centred practice has been found to improve goal achievement and contributed to the experience of mastery as well as a sense of satisfaction with occupational therapy services .

The current study revealed that the enhancement of the participants' life skills, intrinsic abilities, and the adaptation of environmental factors such as reasonable accommodation and social support contributed to the participants' successful RTW experience, as described in theme four. This concurs with a study ${ }^{36}$ that found that employees with mental illness are able to manage their well-being and reintegrate into their worker roles easier when they experience supportive working conditions. Social support (including family, employer, and colleague support) are known to be vital determinants of workplace adaptation and participation through affirmation of employees' worker roles and identities, alleviating anxieties and experiencing perceptions of meaningfulness at work ${ }^{37}$. Participants in the current study adapted to their worker roles when they received and had regular ongoing support after being reasonably accommodated within their working environments.

\section{LIMITATIONS OF THE STUDY}

The current study had two significant limitations. Firstly, only one female participated in the study, compared to eight male participants. The researcher experienced immense difficulty in attempting to identify and recruit an equal number of male and female participants who satisfied the inclusion criteria of the study. Another limitation was that due to agenda clashes and time limitations, some of the interviews were conducted during the participants' lunch break within their work environments, which may have influenced the quality of the data collected.

\section{CONCLUSIONS AND RECOMMENDATIONS}

The current study highlighted the value of the MOOSE as an effective strategy of supported employment, within South Africa, by enabling individuals with schizophrenia to enhance their work skills and facilitate a successful RTW process within the open labour market. A client-centred focus to rehabilitation, the provision of ongoing therapeutic support, and the ability of the MOOSE to facilitate the enhancement of self-efficacy and worker identities contributed to the participants' successful RTW experiences. Furthermore, the adaptation of environmental factors (such as reasonable accommodation) and the presence of social support contributed notably to an easier and more successful RTW process. The authors recommend that therapists encourage the support from family, friends, employers, and work colleagues during the RTW process of their clients. It is further recommended that therapists' network, collaborate and establish working relationships with relevant stakeholders to ensure a holistic supported employment approach to the RTW process.

\section{ACKNOWLEDGEMENTS AND FUNDING DECLARATIONS}

The authors would like to thank the Ruth Watson Research Grant and Crouch Trust for their contribution towards this research.

\section{REFERENCES}

I. Nuechterlein KH, Subotnik KL, Turner LR, Ventura J, Becker DR, Drake RE. Individual placement and support for individuals with recent-onset schizophrenia: Integrating supported education and supported employment. Psychiatric Rehabilitation Journal. 2008; 3I (4): 340-349.

https://doi.org// 0.2975/3I.4.2008.340.349

2. Phanthunane P, Vos T, Whiteford H, Bertram M, Udomratn P. Schizophrenia in Thailand: Prevalence and burden of disease. Population Health Metrics. 2010; 8(24): I-8. https://doi.org/10.1 186/1478-7954-8-24

3. American Psychiatric Association. Diagnostic and statistical manual of mental disorders. 5th ed. Arlington, VA: American Psychiatric Publishing; 2013.

4. Zaprutko T, Kus K, Bilobryvka R, Rakhman L, Göder R, Michalak M, Poglodzinski A, Nowakowska E. Schizophrenia and employment: Evaluation from professional's point of view. Psychiatric Quarterly. 2015; 86(4): 569-579. https://doi.org/ I0.1007/s I I | 26-015-9354-6

5. Van Niekerk L, Coetzee Z, Engelbrecht M, Hajwani Z, Landman S, Motimele M, Terreblanche S. Supported employment: Recommendations for successful implementation in South Africa. South African Journal of Occupational Therap. 20I I; 4I(3): 85-90.

6. Abbas. Exploring the experiences and perceptions of individuals with schizophrenia about the use of the model of occupational self-efficacy in enhancing work skills. 2018. http://hdl.handle.net/ I I394/6525 (08/02/2020).

7. Soeker MS, Pape C. The use of the model of Occupational SelfEfficacy for work retraining: a multiple case study. Occupational Therapy International. 2019; I(I): I-8. https://doi.org//0.1155/2019/3867816

8. Statistics South Africa. Mid-year population estimates. 2017. http://www.statssa.gov.za/publications/P0302/P03022017.pdf (31/0I/2020).

9. Department of Labour. Commission for Employment Equity Annual Report. Pretoria: Government Printer, 2017.

10. Department of Labour. Commission for Employment Equity Annual Report. Pretoria: Government Printer, 2014.

II. Eklund M. Work status, daily activities and quality of life among people with severe mental illness. Quality of Life Research. 2009; I8(2): |63- | 70. https://doi.org/10.1007/s | | |36-008-943|-5 
12. Mueser K, Salyers M, Mueser P. A prospective analysis of work in schizophrenia. Schizophrenia Bulletin. 200I; 27(2): 28I-296. https://doi.org/10.1093/oxfordjournals.schbul.a006874

13. Martini LC, Neto JB, Petreche B, Fonseca AO. Schizophrenia and work: Aspects related to job acquisition in a follow-up study. Brazilian Journal of Psychiatry. 2017; 40(I): 35-40.

https://doi.org//0.1590/I516-4446-2016-2128

14. The National Council for Persons with Physical Disabilities in South Africa. Numbers of disabled people employed has dropped below 1\%. 2016. http://www.capetalk.co.za/articles//47/3/numbers-ofdisabled-people-employed-has-dropped-below-I (07/02/2020).

15. Maja PA, Mann WM, Sing D, Steyn AJ, Naidoo P. Employing people with disabilities in South Africa. South African Journal of Occupational Therapy. 20II; 4I(I): 24-32.

16. Bond GR, Drake RE. Making the case for IPS supported employment. Administration and Policy in Mental Health and Mental Health Services Research. 2012; 39(6): I-5. https://doi.org/I0.1007/s 10488-0 I 2-0444-6

17. Kawohl W, Moock J, Heuchert S, Rössler W. Job maintenance by supported employment: an overview of the 'supported employment plus' trial. Frontiers in Public Health. 20I5; 3(I40): I-5. https://doi.org/10.3389/fpubh.2015.00140

18. Brown JD, Barret A, Ireys H, Caffery E, Hourihan K. Evidence-based practices for medicaid beneficiaries with schizophrenia and bipolar disorder. Washington, DC: Office of Disability, Aging and Long-Term Care Policy; 2012.

19. McKay C, Nugent KL, Johnsen M, Eaton WW, Lidz CW. A systematic review of evidence for the clubhouse model of psychosocial rehabilitation. Administration and Policy in Mental Health and Mental Health Services Research. 2018; 45(I): 28-47.

https://psycnet.apa.org/doi/10.1007/s 10488-016-0760-3

20. Raeburn T, Halcomb E, Walter G, Clearly M. An overview of the clubhouse model of psychiatric rehabilitation. Australasian Psychiatry. 20I3; 21 (4): 376-378.

https://doi.org//0.1 I77/1039856213492235

21. Soeker MS. The efficacy of the Model of Occupational Self Efficacy for returning brain injured individual to work: A pre post intervention study. Work. 2017; 58(I): 63- 72.

https://doi.org/10.3233/wor-172603

22. Soeker MS. A pilot study on the operationalization of the Model of Occupational Self Efficacy: a model for the reintegration of persons with brain injuries to their worker roles. Work. 2016; 53(I): 523534. https://doi.org//0.3233/wor-152229

23. Denzin NK, Lincoln YS. Handbook of qualitative research. 3rd ed. Thousand Oaks, CA: Sage Publication; 2005.

24. Crowe $M$, Inder M, Porter R. Conducting qualitative research in mental health: Thematic and content analyses. Australian and New Zealand Journal of Psychiatry. 2015; 49(7): 616-623. https://doi.org//0.1 I77/00048674I5582053

25. Braun V, Clarke V. Using thematic analysis in psychology. Qualitative Research in Psychology. 2006; 3(2): 77-101. https://doi.org/10.1191/1478088706qp063oa

26. Henning E, van Rensburg W, Smit B. Theoretical frameworks, conceptual frameworks and literature reviews. In: Henning $E$, van Rensburg W, Smit B, editors. Finding your way in qualitative research. Pretoria: Van Schaik; 2004:I2-27.

27. Curtin M, Fossey E. Appraising the trustworthiness of qualitative studies: Guidelines for occupational therapists. Australian Occupational Therapy Journal. 2007; 54(2): 88-94. https://doi.org/I0.1 I I I/j. I440-1630.2007.0066I.x

28. Mcsotho L, Louw D, Calitz FJW. Schizophrenia among Sesotho speakers in South Africa. African Journal of Psychiatry. 20 I I; I4(I): 50-55

https://doi.org/ I0.43 |4/ajpsy.v| 4il .65473

29. Vandewalle J, Debyser B, Beeckman D, Vandecasteele T, Deproost E, Hecke AV, Verhaeghe S. Constructing a positive identity: A qualitative study of the driving forces of peer workers in mental health-care systems. International Journal of Mental Health Nursing. 2018; 27(I): 378-389.

https://doi.org/10.11 I I/inm. 12332

30. Wegner L, Struthers P, Mohamed S. "The pen is a powerful weapon; it can make you change": The value of using reflective writing with adolescents. South African Journal of Occupational Therapy. 2017; 47(3): II-16. https://doi.org/10.17/59/2310-3833/2017/v47n3a3

31. Lexén A, Hofgren C, Stenmark R, Bejerholm U. Cognitive functioning and employment among people with schizophrenia in vocational rehabilitation. Work. 2016; 54(3): 735-744.

https://doi.org/10.3233/wor-162318

32. Soeker MS. Adaptation to the worker role: The vocational experience of South African male ex-offenders. Occupational Medicine \& Health Affairs. 2014; 2(2): I-8. https://doi: 10.4I72/2329-6879.1000I53

33. Mingrone C, Rocca P, Castagna F, Montemagni C, Sigaudo M, Scalese M, Rocca G, Bogetto F. Insight in stable schizophrenia: Relations with psychopathology and cognition. Comprehensive Psychiatry. 2013; 54(5): 484-492. https://doi.org/10.1016/j.comppsych.2012.12.014

34. Zhornitsky S, Potvin S, Aubin G, Stip E. Relationship between insight into cognition, extrapyramidal symptoms and mental illness in schizophrenia. The Royal Australian and New Zealand College of Psychiatrists. 201 I; 45(7): 596-597. https://doi.org/10.3109/00048674.201 I.56/483

35. Flaubert JL, Spicer CM, Jette AM. The promise of assistive technology to enhance activity and work participation. Washington (DC): National Academies Press (US); 2017.

https://www.ncbi.nlm.nih.gov/books/NBK453285/ (23/03/2020).

36. PaloJ, Rothmann $S$. Work engagement in the mining industry in South Africa: The role of tasks and relationships. Journal of Psychology in Africa. 2016; 26(3): 221-229. https://doi.org/10.1080/14330237.2016.1 I8590 I

37. Kahn W, Heaphy ED. Relational contexts of personal engagement at work. In Truss C, Delbridge R, Soane E, Alfes K, Shantz, A. (eds.), Employee engagement in theory and practice. Abingdon: Routledge; 2014.

\section{AUTHOR CONTRIBUTIONS}

lesrafeel Abbas conducted the research and wrote the article under the supervision and guidance of Prof. Mogammad Shaheed Soeker Prof. Mogammad Shaheed Soeker contributed to the writing of and edited the article.

Corresponding Author

* Iesrafeel Abbas

Email: iesrafeel.abbas@uct.ac.za 